\title{
Phenotyping Study of Cyclophosphamide 4-Hydroxylation in Malay Cancer Patients
}

This article was published in the following Dove Press journal:

Drug Design, Development and Therapy

\author{
Yesi Ihdina Fityatal Hasanah (D) \\ Yahdiana Harahap (D) ${ }^{1,2}$ \\ Denni Joko Purwanto ${ }^{3}$ \\ 'Bioavailability and Bioequivalence \\ Laboratory, Faculty of Pharmacy, \\ Universitas Indonesia, Depok, Indonesia; \\ ${ }^{2}$ Indonesia Defense University, Bogor \\ 168I0, West Java, Indonesia; ${ }^{3}$ Functional \\ Medical Staff of Surgical Oncology, \\ Dharmais Cancer Hospital, Jakarta, \\ Indonesia
}

Background: Cyclophosphamide (CP) is an anticancer alkylating group (nitrogen mustard) and a prodrug that will be metabolized to form its active metabolite, 4-hydroxycyclophosphamide (4-OHCP). The various enzymes involved in its bioactivation can cause a wide range of $\mathrm{CP}$ expression and activity among patients and ultimately affect the metabolism, efficacy and toxicity of this drug. The effectiveness of CP therapy can be determined by 4 OHCP level in dried blood spot (DBS).

Aim: The purpose of this study was to conduct the phenotyping of CP 4-hydroxylation rate in Malay cancer patients.

Methodology: Phenotyping study of CP 4-hydroxylation rate to 40 subjects of Malay cancer patients was done based on the value of its bioactivity ratio (4-OHCP to CP levels). Results: The result shown the cyclophosphamide 4-hydroxylation rate of $80 \% \quad(n=32)$ subjects as ultrarapid metabolizer (UM) and $20 \%(n=8)$ as poor metabolizer (PM).

Conclusion: Phenotyping study of CP 4-hydroxylation in Malay cancer patients can be conducted by quantifying CP bioactivity ratio (4-OHCP to CP level) in dried blood spot. In majority of Malay cancer patients, cyclophosphamide would be bioactivated through 4hydroxylation in hepar rapidly as indicated by the high value of the bioactivity ratio or the increased CP clearance and 4-OHCP level.

Keywords: 4-hydroxycyclophosphamide, 4-OHCP, 4-hydroxylation rate, cyclophosphamide, $\mathrm{CP}$, dried blood spots, DBS, Malay ethnicity

\section{Introduction}

Cyclophosphamide (CP) is a nitrogen mustard, alkylating cytotoxic drug with a broad clinical spectrum for treatment of autoimmune disorders and various types of cancers like chronic lymphocytic leukemia, lymphomas, soft tissue and osteogenic sarcoma, and solid tumours (lung, breast, and ovary). ${ }^{1} \mathrm{CP}$ is given singly or in combination with other agents, orally or by intravenous injection or infusion. Up to $70-80 \%$ of CP is metabolized by the liver microsomal enzymes and yields its active metabolite, 4hydroxycyclophosphamide (4-OHCP). The drug-metabolizing enzymes (DME) involved in the bioactivation are CYP2A6, CYP2B6, CYP3A4, CYP3A5, CYP2C9, CYP2C18, and CYP2C19, with CYP2B6 providing the greatest activity. In the systemic circulation, 4-OHCP is in equilibrium with its tautomeric, aldophosphamide, which will be hydrolyzed spontaneously by nonenzymatic $\beta$-elimination to phosphoramide mustard and acrolein. Phosphoramide mustard is cross-linked (covalent) with DNA intraand interstrand, thus inhibiting DNA replication and causing cell apoptosis. ${ }^{2-5}$

Several CP detoxification pathways compete with phosphoramide mustard formation and thus affect phosphoramide mustard levels. CP can undergo N-dechloroethylation
Correspondence: Yahdiana Harahap Griya Depok Asri Blok G3 No. I, Depok City, West Java I64II, Indonesia

Email yahdiana@farmasi.ui.ac.id 
which is catalyzed mainly by CYP3A4 to form 2-dechloroethylcyclophosphamide metabolite which is equimolar with chloroacetaldehyde by-products. ${ }^{3}$ This minor pathway accounts for approximately $19 \%$ of the total CP clearance. Besides, 4-OHCP undergoes secondary metabolism by CYP3A4 to form inactive 4-ketocyclophosphamide. The intermediate product (imino-cyclophosphamide) in this reaction can also undergo glutathione conjugation. Alcohol dehydrogenase and aldo-keto reductase also play a minor role in the elimination of aldophosphamide by reducing them to alcophosphamide. In contrast, the oxidation of aldophosphamide to carboxyphosphamide, catalyzed by ALDH1A1 and $A L D H 3 A 1$, is an important inactivation pathway. Less than $20 \%$ of the CP dose is eliminated in the urine in its entirety. Between 30 and $60 \%$ of total CP is eliminated in the kidney in the form of major metabolite and the remainis eliminated through feces. ${ }^{2,3,6}$

The CP chemotherapy effectiveness is determined by the active metabolite, 4-OHCP, level in the blood, which is formed through 4-hydroxylation. The various enzymes involved in $\mathrm{CP}$ metabolism can cause a wide range of $\mathrm{CP}$ expression and activity among individuals, and ultimately affect the pharmacokinetic, efficacy, and toxicity of this drug. A wide variability of the CP 4-hydroxylation rate between individuals (100 folds) can affect the drug pharmacokinetics (elimination rate and drug level) so that it gives different responses (efficacy and toxicity) among patients. Genetic factors (polymorphism) and environment factors such as diet, smoking, alcohol, drugs, disease, age, and sex can affect the manifestation of CP 4hydroxylation. ${ }^{7}$

Given the complex scheme of CP metabolism, it is clear that many pathways can affect the interindividual variability of $\mathrm{CP}$ response. However, most pharmacogenomic studies have focused on assessing the genetic variant of CYP2B6, an enzyme that catalyzes the initial bioactivation step. The CYP2B6 gene is located on chromosome $19 \mathrm{q} 13.2$, ranges in $\sim 26 \mathrm{~kb}$ region, consists of nine exons, and encodes for 491 amino acids. ${ }^{8}$ CYP2B6 SNP coding region changes the function and expression (activity) of the enzyme produced, which can vary depending on the substrate. ${ }^{9,10}$ CYP2B6 is highly induced and can be auto-induced by $\mathrm{CP}$ within $24 \mathrm{~h}$ after continuous infusion or after repeated administration for several days. ${ }^{11}$ Increased CP activation will increase the 4-OHCP levels and CP clearance. ${ }^{12}$ The pharmacogenetics of $C Y P 2 B 6$ is very complex because SNPs encoding common proteins can exist in various haplotype combinations. This causes the distribution of allele variant frequencies in each population to be very diverse.

The CYP2B6*6 allele variant with the greatest prevalence was found in the Caucasian population $(26 \%),{ }^{13}$ Japan (16\%), ${ }^{14}$ West Africa (42\%), and Papua New Guinea (62\%). ${ }^{8}$ The CYP2B6 *8 allele was found at low frequency $(\sim 1 \%)$ in the Caucasian population and was absent in African American, Hispanic, and Asian subjects. ${ }^{15}$ In the Timor population (East Nusa Tenggara, Indonesia), CYP2B6*9, $* 4$, and *6 were found to be respectively; $40.6 ; 29.2$; and $22.9 \%{ }^{16}$ The CP 4-hydroxylation rate by $C Y P 2 B 6$ was categorized into poor metabolizer (PM) (*6 and/or *7), extensive metabolizer (EM) $(* 5$ and wild type), and ultra rapid metabolizer (UM) $(* 4) .{ }^{17}$ Based on other literature, CYP2B6*6/ $* 6$ and $* 6 / * 7$ were classified as PM, CYP2B6*1/*1 (wild type), $* 1 / * 5, * 1 / * 6, * 1 / * 7$, and $* 5 / * 5$ was classified as EM, and CYP2B6 *1/*4, *4/*5, and *4/*6 were classified as UM. ${ }^{13,18,19}$ Classification of 4-hydroxylationratetypeof CYP2B6 alleles is still inconsistent with several studies. The Xie et al study found that the CYP2B6 G516T allele variant $(n=8)$ had an average bioactivity ratio and CP clearance two times greater than the wild type $(n=21)$ with values $(0.027 \pm 0.0020)$ and $(0.017 \pm 0.0014)$, and $(8.13 \pm 4.23 \mathrm{~L} / \mathrm{h})$ and $(5.13 \pm 1.67 \mathrm{~L} / \mathrm{h}){ }^{20}$ Allele variants with the G516T mutation are known to be present in $C Y P 2 B 6 * 6, * 7$, and *9. From several studies, $C Y P 2 B 6 * 6$ allele variant carrier had greater 4-hydroxylation activity than noncarriers. ${ }^{11,20-22}$ However, in a study on Japanese patients, correlation between the CP 4hydroxylation rate with $C Y P 2 B 6 * 6$ and $* 9$ alleles was not found. ${ }^{6}$ Differences between study results might be due to several factors including ethnicity, number of subjects, CP dose, or co-medication.

The interindividual variability of CP metabolism influenced the differences on $\mathrm{CP}$ toxicity and efficacy profile among patients. The CP metabolism is a manifestation of genetic expression (DME genetic polymorphism factor) combined with the environment factors (diet, lifestyle, co-medication, comorbidity, age, sex, pollutants, etc) so that phenotypes are not always correlated according to the genotype. ${ }^{7,11}$ However, some researchers still consider genetic factors to play a relatively large role in influencing the metabolic phenotype compared to other factors. The genotype is a detailed gene structure in an individual whereas phenotype is more commonly measured using drugs as a marker of a particular DME and measuring the ratio of metabolite levels to their parent drug. ${ }^{23}$ Polymorphisms that occur in individuals will continue to be passed down to the next generation so that the 
frequency of polymorphisms in each ethnicity or population varies. Therefore, there is a need for personalized medicine and the provision of safe, effective, and rational therapeutic doses in a population. Research on the metabolic activity of $\mathrm{CP}$ has been widely carried out but is limited to populations in developed countries such as countries in Europe, USA, Japan, and China. ${ }^{13,14,24}$ However, there have been no studies related to the activity (rate) of CP 4-hydroxylation metabolism in the population in Indonesia until now. This underlies the need for a phenotypic study of the CP 4-hydroxylation rate in cancer patients, especially those of the Malay ethnicity, which is the largest ethnic group in Indonesia. Malay, also known as the Mongoloid ethnicity, is considered to be the ancestors of the Indonesian nation and differentiated into ProtoMalay and Deutro-Malay. ${ }^{25,26}$ In this phenotyping study, the CP 4-hydroxylation will be determined by calculating the $\mathrm{CP}$ bioactivity ratio (4-OHCP to $\mathrm{CP}$ level) in dried blood spot (DBS) of Malay cancer patients which analyzed using UPLC-MS/MS with internal standard SIL 4-OHCP-d4.

\section{Materials and Methods}

\section{Chemicals}

Cyclophosphamide (CP) and semicarbazide hydrochloride as derivatization agent were purchased from Sigma-Aldrich (Singapore). 4-hydroxycyclophosphamide (4-OHCP) kit and internal standard (IS) 4-hydroxycyclophosphamide-d4 kit (4-OHCP-d4) were purchased from Toronto Research Chemicals (USA). Methanol (HPLC grade), acetonitrile (HPLC Grade), and formic acid was purchased from Merck (Darmstadt, Germany). Ultrapure water was prepared by using a Millipore Direct-Q ${ }^{\text {TM }} 5$ water system (Millipore, Watford, Hertfordshire, UK). Perkin Elmer 226 DBS card was obtained from PerkinElmer (USA).

\section{Subjects}

Dried blood spots (DBS) samples were acquired with written informed consent from cancer patients from "Dharmais" Cancer Hospital, Jakarta, Indonesia. Subjects were interviewed for ethnicity background for three generations background. This study was reviewed and approved by the Research Ethics Committees of "Dharmais" Cancer Hospital, Jakarta 11,420, Indonesia (No. 150/KEPK/VII/2019). Subjects were eligible for this study if they were 18-65 years old cancer patients of Malay ethnicity who received intravenous infusion of $\mathrm{CP}$ as their chemotherapy regimen. Subjects who were contraindicated with $\mathrm{CP}$ and had liver and kidney disorders were excluded from the study. DBS samples were collected after complete the $\mathrm{CP}$ infuse on by finger-prick through the fingertips using a lancet, collected in a tube, and spotted immediately on DBS card which contain dried semicarbazide derivative agent.

\section{Method Validation}

Full validation of $\mathrm{CP}$ and 4-OHCP analysis method in DBS was conducted based on the Food and Drug Administration (2018) and European Medicines Agency (2011) guidelines for validation of bioanalysis, by validating LLOQ, linearity, accuracy and precision, selectivity, carryover, recovery, dilution integrity, matrix effect, and stability. ${ }^{27,28}$

\section{Cyclophosphamide 4-Hydroxylation Assay} Cyclophosphamide 4-hydroxylation was measured by quantifying $\mathrm{CP}$ and 4-OHCP in DBS samples with internal standard SIL 4-OHCP-d4 by UPLC-MS/MS. Due to 4-OHCP instability, it carried out on-card DBS derivatization. Initially, the DBS card was spotted by $50 \mu \mathrm{L}$ semicarbazide $2 \mathrm{M}$ and air-dried for two hours. Blood samples were spotted $30 \mu \mathrm{L}$ on the DBS card and air-dried for three hours. Blood spots were cut off completely and added by $20 \mu \mathrm{L}$ internal standard 4OHCP- $\mathrm{d}_{4} 1 \mathrm{mg} / \mathrm{mL}$ and $1000 \mathrm{~mL}$ methanol. The mixture was vortexed for two minutes, sonicated for $10 \mathrm{~min}$, and centrifugated for five minutes at $10,000 \mathrm{rpm}$. Aliquots of $850 \mu \mathrm{L}$ of supernatant was evaporated at $60^{\circ} \mathrm{C}$ for 15 min under $\mathrm{N}_{2}$ gas flow. The residue was reconstituted by $100 \mu \mathrm{L}$ of the mobile phase, sonicated for one minute, vortexed for 30 seconds, and centrifuged for five minutes at 10,000 rpm. Afterward, $10 \mu \mathrm{L}$ of aliquot was injected into the ultra-high-pressure liquid chromatography-tandem mass spectrometry (UPLC-MS/ MS) system.

$\mathrm{CP}$ and 4-OHCP in DBS were quantified using ESI+ ionization method (Waters Xevo TQD Triple Quadrupole). Chromatographic separation was performed using a UPLC $\mathrm{H}-\mathrm{Class}$ Acquity column $\mathrm{BEH} \mathrm{C}_{18}(100 \dot{\mathrm{x}} 2.1 \mathrm{~mm}, 1.7 \mu \mathrm{m})$ maintained at $50^{\circ} \mathrm{C}$. The flow rate was $0.20 \mathrm{~mL} / \mathrm{min}$, and the mobile phase was $0.01 \%$ formic acid as eluent $\mathrm{A}$ and acetonitrile as eluent $\mathrm{B}$. The gradient program was as follows: initial elution with $75 \% \mathrm{~A}$, followed by a linear gradient to $10 \% \mathrm{~A}$ from 0 to $1.0 \mathrm{~min}$ and maintained for $1.0 \mathrm{~min}$, to $75 \%$ A from 2.0 to $2.5 \mathrm{~min}$ and maintained for $2.5 \mathrm{~min}$ until the end of the run. The quantitation was conducted using multiple reaction monitoring (MRM) and the quantitation traces were $261.03>140.16$ (cone 
voltage, $34 \mathrm{~V}$; collision voltage, $22 \mathrm{~V}$ ) for $\mathrm{CP}, 334.10$ $>221.04$ (cone voltage, $16 \mathrm{~V}$; collision voltage, $14 \mathrm{~V}$ ) for 4-OHCP-semicarbazone and $338.10>225.06$ (cone voltage, $10 \mathrm{~V}$; collision voltage, $10 \mathrm{~V}$ ) for IS 4-OHCP-d4semicarbazone. The optimized parameters for MS were as follows: capillary voltage, $3.5 \mathrm{kV}$; gas desolvation temperature and flow rate, $350^{\circ} \mathrm{C} ; 500 \mathrm{~L} / \mathrm{h}$, respectively. Calibration range was $10-40,000 \mathrm{ng} / \mathrm{mL}$ for $\mathrm{CP}$ and $5-$ $4000 \mathrm{ng} / \mathrm{mL}$ for $4-\mathrm{OHCP}$, at seven levels of concentration for each. Cyclophosphamide 4-hydroxylation rate was determined by bioactivity ratio of $\mathrm{CP}$ which can be calculated by dividing 4-OHCP level to $\mathrm{CP}$ level ([4$\mathrm{OHCP}]:[\mathrm{CP}])$.

\section{Results and Discussion}

\section{Method Validation}

Linearity and LLOQ

Calibration curves obtained were linear in the concentration range within $10-40,000 \mathrm{ng} / \mathrm{mL}$ for $\mathrm{CP}$ and $5-4000 \mathrm{ng} / \mathrm{mL}$ for 4-OHCP, with correlation coefficient $(\mathrm{r} \geq 0.9980)$ and LLOQ 10 and $5 \mathrm{ng} / \mathrm{mL}$, respectively.

\section{Selectivity}

Retention times of CP, 4-OHCP, and IS were 3.13; 1.94; and $1.91 \mathrm{~min}$, respectively. There was no significant interfering peak observed around the CP, 4-OHCP, and IS, due to endogenous components or reagents.

\section{Accuracy and Precision}

Quality control samples were run a five replicates at four concentration levels for each analyte, which were: $10 \mathrm{ng} /$ $\mathrm{mL}$ (LLOQ), $30 \mathrm{ng} / \mathrm{mL}$ (QCL), 20,000 ng/mL (QCM), $30,000 \mathrm{ng} / \mathrm{mL}(\mathrm{QCH})$ for $\mathrm{CP}$ and $5 \mathrm{ng} / \mathrm{mL}$ (LLOQ), 15 ng/mL (QCL), 2000 ng/mL (QCM), 3000 ng/mL (QCH) for 4-OHCP by within-run and between-run. They fulfill the requirement if \%diff and $\% \mathrm{CV}$ obtained within $15 \%$, except for LLOQ $20 \%$. The intra-batch accuracy and precision performed on LLOQ, QCL, QCM, and QCH shown in Table 1 were within the acceptable criteria based on FDA 2018 and EMA 2011 guidelines. $^{27,28}$

\section{Carryover}

There was no carryover found in the blank sample after the injection of the highest concentration (ULOQ) sample. The carryover still met the requirements for analytes $<20 \%$ and $<5 \%$ for IS, which CP, 4-OHCP, and IS were $17.53,1.48$, and 0.01 , respectively.
Table I Accuracy and Precision of $\mathrm{CP}$ and 4-OHCP

\begin{tabular}{|l|l|l|l|l|}
\hline Analyte & QC & $\begin{array}{l}\text { Conc. } \\
\text { (ng/mL) }\end{array}$ & $\begin{array}{l}\text { Accuracy } \\
\text { (\%diff) }\end{array}$ & $\begin{array}{l}\text { Precision } \\
\text { (\%CV) }\end{array}$ \\
\hline \multirow{2}{*}{ CP } & LLOQ & 10 & 2.57 & 6.25 \\
& QCL & 30 & 1.72 & 5.04 \\
& QCM & 20,000 & 8.83 & 3.32 \\
& QCH & 30,000 & 13.77 & 4.26 \\
\hline \multirow{3}{*}{$4-\mathrm{OHCP}$} & LLOQ & 5 & 5.19 & 5.55 \\
& QCL & 15 & 1.22 & 9.55 \\
& QCM & 2000 & 7.12 & 3.84 \\
& QCH & 4000 & 14.86 & 4.22 \\
\hline
\end{tabular}

\section{Recovery and Matrix Effect}

The extraction recoveries of $\mathrm{CP}$ at three levels of concentration QCL, QCM, and QCH were 85.02-95.69\% and 4-OHCP were 75.18-94.55\%. The matrix effect of CP, 4-OHCP, and IS obtained were fulfilled the $\% \mathrm{CV}$ criteria for both matrix factor and internal standard normalized matrix factor, not exceeding $\pm 15 \%$. There was no significant matrix effect observed.

\section{Dilution Integrity}

Dilution process was conducted in human blank whole blood until QCH and half QCH concentration. Dilution integrity obtained was acceptable and still fulfils accuracy and precision requirements with \%diff and $\% \mathrm{CV}$ not more than $15 \%$.

\section{Stability}

Stock solutions storage of CP, 4-OHCP, and IS 4-OHCP$\mathrm{d} 4$ in water at room temperature for $24 \mathrm{~h}$ and in the freezer $\left(-80^{\circ} \mathrm{C}\right)$ for 30 days (long-term stability) did not alter the analyte of CP, 4-OHCP, and IS 4-OHCP-d4. The stability test results of $\mathrm{CP}$ and 4-OHCP in DBS were stable enough during sample preparation, storage conditions and autosampler.

\section{Cyclophosphamide 4-Hydroxylation Assay}

All subjects who met the inclusion and exclusion criteria were 40 Malay women. Subject interviews were conducted after signing the informed consent to obtain subject information related to ethnic and tribe backgrounds, lifestyle, and physiological condition. All subjects were patients receiving two-hour prolonged $\mathrm{CP}$ infusions. About $200 \mu \mathrm{L}$ blood sample was taken by finger-prick, after two hours CP administration. The blood was immediately spotted onto the DBS card containing dried semicarbazide 
and air-dried for three hours. The blood sampling time at two hours was based on the $t_{\max }$ of active metabolites 4OHCP $(2.1 \pm 2.5 \mathrm{~h})$ and $\mathrm{CP}(1.7 \pm 1.3 \mathrm{~h})$ so expected that 4 OHCP has been optimally formed and CP can still be detected in large quantities. ${ }^{29}$ Blood sampling at the elimination time (four hours) after $\mathrm{CP}$ administration was not possible due to patient unwillingness and over hospital operating hours. Blood spotting $(30 \mu \mathrm{L})$ on DBS card must be done immediately because 4-OHCP $t_{1 / 2}$ in blood at $37^{\circ} \mathrm{C}$ is about four minutes. ${ }^{30}$

The characteristic data of the subjects is shown in Table 2. A total of 38 subjects $(95 \%)$ were breast cancer patients while two subjects (5\%) were non-Hodgkin's lymphoma cancer patients. Various combination of chemotherapy regimen were given to patients: 27 subjects $(67.5 \%)$ were given the FAC chemotherapy regimen (fluorouracil +adriamycin+cyclophosphamide), six subjects (15\%) AC (adriamycin+cyclophosphamide), ffour subjects (10\%) TAC (docetaxel+adriamycin+cyclophosphamide), two patients (5\%) RCHOP (rituximab+cyclophosphamide +adriamycin+vincristine+prednisone), and one subject (2.5\%) TC (docetaxel+cyclophosphamide). Subjects

Table 2 Characteristic of Subjects

\begin{tabular}{|c|c|}
\hline Characteristic & $n=40$ \\
\hline \multicolumn{2}{|l|}{ Age (years) } \\
\hline Mean \pm SD & $43.6 \pm 9.54$ \\
\hline Median (min-max) & $42(23-63)$ \\
\hline \multicolumn{2}{|l|}{ Weight (kg) } \\
\hline Mean $\pm S D ;(\min -\max )$ & $59.3 \pm 9.81 ;(38-85)$ \\
\hline \multicolumn{2}{|l|}{ Cancer Type (n) } \\
\hline Breast Cancer & $38(95.0 \%)$ \\
\hline LNH & $2(5.0 \%)$ \\
\hline \multicolumn{2}{|l|}{ Chemotherapy Regimen (n) } \\
\hline FAC & 27 (67.5\%) \\
\hline $\mathrm{AC}$ & $6(15.0 \%)$ \\
\hline TAC & $4(10.0 \%)$ \\
\hline $\mathrm{RCHOP}$ & $2(5.0 \%)$ \\
\hline $\mathrm{TC}$ & I (2.5\%) \\
\hline \multicolumn{2}{|l|}{ CP Dose (mg) } \\
\hline Mean \pm SD; (min-max) & $804.8 \pm$ II9.86; (510-I.100) \\
\hline \multicolumn{2}{|l|}{ CP Dose (mg/kg) } \\
\hline Mean $\pm S D ;(\min -\max )$ & $13.72 \pm 1.88 ;(10-20)$ \\
\hline \multicolumn{2}{|l|}{ CP Dose $\left(\mathrm{mg} / \mathrm{m}^{2}\right)$} \\
\hline Mean $\pm S D ;(\min -\max )$ & $508.0 \pm 56.4 ;(40 \mathrm{I}-69 \mathrm{I})$ \\
\hline
\end{tabular}

Abbreviations: $\mathrm{A} / \mathrm{H}$, doxorubicin; $\mathrm{C}$, cyclophosphamide; $\mathrm{F}$, fluorouracil; $\mathrm{O}$, vincristine; $\mathrm{P}$, prednisone; $\mathrm{R}$, rituximab; $\mathrm{T}$, docetaxel. received an intravenous infusion of $\mathrm{CP}$ chemotherapy with doses varying between 510 and $1100 \mathrm{mg} ; 10-20 \mathrm{mg} / \mathrm{kg}$ body weight; or $401-691 \mathrm{mg} / \mathrm{m}^{2}$ body area. The average given CP dose was $804.8 \pm 119.86 \mathrm{mg} ; 13.7 \pm 1.88 \mathrm{mg} / \mathrm{kg}$; or $508.0 \pm 56.40 \mathrm{mg} / \mathrm{m}^{2}$. The given CP dose is in accordance with standard intravenous CP chemotherapy protocol, which is between 500 and $1000 \mathrm{mg} / \mathrm{m}^{2}$ and is usually done without considering other variables such as age, genetic factors, and comorbid conditions. ${ }^{31}$

The results of the analysis of $\mathrm{CP}$ and 4-OHCP levels in DBS can be seen in Table 3. CP and the active metabolite 4-OHCP were found in all DBS samples. CP was found with the lowest levels in SN 01 at $4699 \mathrm{ng} / \mathrm{mL}$, while the highest levels were found in SN 26 at $39,859 \mathrm{ng} / \mathrm{mL}$. The mean CP level was found at $23,790 \pm 11,472.52 \mathrm{ng} / \mathrm{mL}$ with $48.22 \% \mathrm{CV}$ value. The active metabolite $4-\mathrm{OHCP}$ was found with the lowest levels in SN 01 at $281 \mathrm{ng} / \mathrm{mL}$ and the highest levels were found in SN 22 at $946 \mathrm{ng} / \mathrm{mL}$. The mean 4-OHCP metabolite level was found at $599 \pm 158.95$ $\mathrm{ng} / \mathrm{mL}$ with $26.54 \% \mathrm{CV}$ value. The bioactivity ratio is calculated from dividing the 4-OHCP metabolites levels against the CP prodrug levels in DBS and can be seen in Figure 1 and Table 3. The lowest ratio bioactivity ([4$\mathrm{OCP}]:[\mathrm{CP}]$ ) was found in SN 16 at 0.0112 , while the highest ratio was found in $\mathrm{SN} 09$ at 0.0975 , and the mean ratio was found at $0.0348 \pm 0.02378$ with $68.34 \%$ $\mathrm{CV}$ value.

Determination of the type of drug metabolism rate can be seen phenotypically based on the bioactivity ratio value, ${ }^{11}$ but no literature has published for the classification of the three types of CP 4-hydroxylation rate (PM, EM, and UM) with the limiting value of the bioactivity

Table 3 Phenotype Analysis of Subjects

\begin{tabular}{|c|c|}
\hline Characteristic & $n=40$ \\
\hline \multicolumn{2}{|l|}{ CP levels (ng/mL) } \\
\hline Mean $\pm S D ;(\min -\max )$ & $23,790 \pm$ I I,472.5; (4699-39,859) \\
\hline \multicolumn{2}{|l|}{ 4-ОHCP levels (ng/mL) } \\
\hline Mean $\pm S D ;(\min -\max )$ & $599 \pm 159.0 ;(28 \mid-946)$ \\
\hline \multicolumn{2}{|c|}{ Phenotype (bioactivity ratio) } \\
\hline \multicolumn{2}{|c|}{ PM (<0,0I70; n=8; 20\%) } \\
\hline Mean \pm SD & $0.0139 \pm 0.0019$ \\
\hline Median (min-max) & $0.014 I(0.0112-0.0164)$ \\
\hline \multicolumn{2}{|l|}{ UM ( $\geq 0,0170 ; n=32 ; 80 \%)$} \\
\hline Mean \pm SD & $0.0400 \pm 0.0239$ \\
\hline Median (min-max) & $0.0309(0.0174-0.0975)$ \\
\hline
\end{tabular}

Abbreviations: PM, poor metabolizer; UM, ultrarapid metabolizer. 


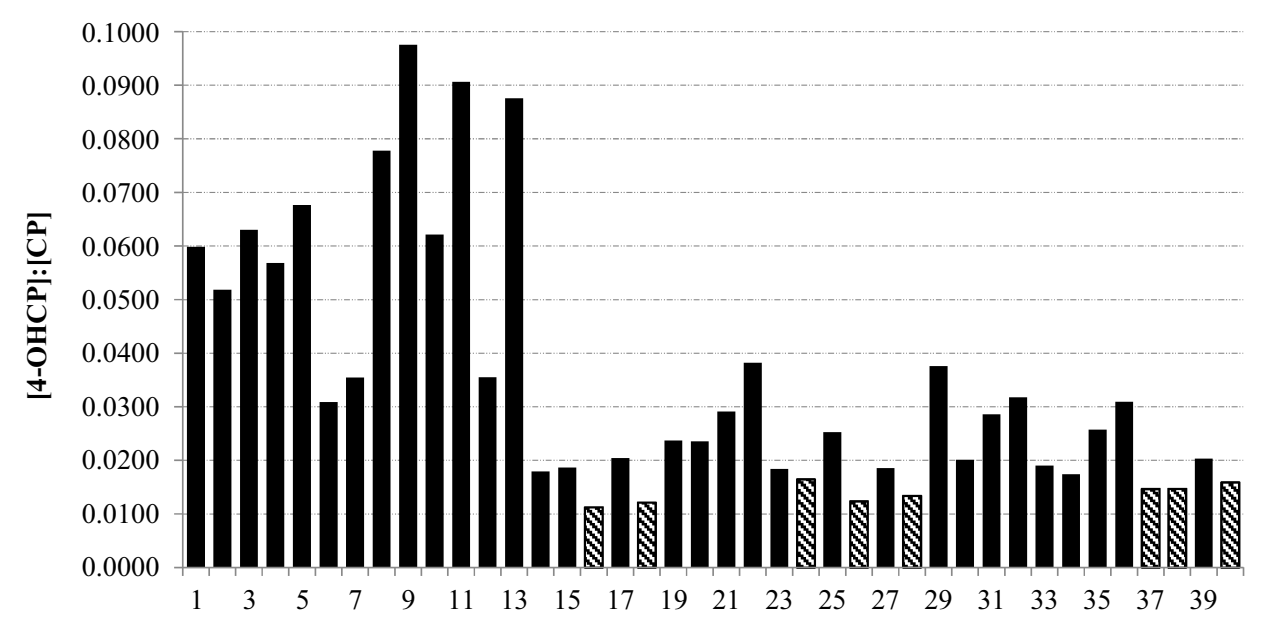

Figure I CP bioactivity ratio [4-OHCP]:[CP] on subjects.

Note: Black dashed-line shows a limit bioactivity ratio of 0.0170 .

ratio. Previously it has been agreed in some literature that CYP2B6 wild type is categorized as extensive metabolizer (EM) type. ${ }^{11,13,17-19}$ Therefore, the (mean) wild type bioactivity ratio of $0.0170,{ }^{20}$ can be used as the standard limit for the EM value, so that the CP 4-hydroxylation type is classified into two types, namely PM if the bioactivity ratio value is $<0.0170$ and the UM for the bioactivity ratio value is $\geq 0.0170$. In this study, the results showed that from all 40 subjects of Malay cancer patients, $80 \%$ of subjects ( $\mathrm{n}=32)$ was classified as UM and $20 \%$ of subjects $(n=8)$ was PM (Table 3). The profile of the distribution of the bioactivity ratio values in the two $\mathrm{CP}$ 4-hydroxylation groups, namely poor metabolizers and ultrarapid metabolizers, is shown in Figure 2 and it can be seen that although the data distribution is not symmetrical, extreme data or outliers are not found.

The UM phenotype indicates that $\mathrm{CP}$ will be bioactivated through 4-hydroxylation in hepar rapidly as indicated by the high value of the bioactivity ratio or the increased $\mathrm{CP}$ clearance and 4-OHCP level. The prevalence result of CP metabolism phenotypes in this study corresponded with several previous studies in other ethnicities. . $^{81,13,14,16,20-22,24}$ Based on these other studies, it can be estimated that in Malay ethnicity the majority of the CP 4-hydroxylation phenotype type is obtained as a UM which might be genetically derived from the $C Y P 2 B 6 * 6$ allele variant.

High 4-OHCP level on ultrarapid metabolizer can improve cancer therapy response better but alternatively, it also increases toxicity. ${ }^{12}$ Unlike other side effects (myelosuppression, dysuria, nausea, vomiting, alopecia, cardiotoxicity, hypersensitivity, immunosuppression) that can

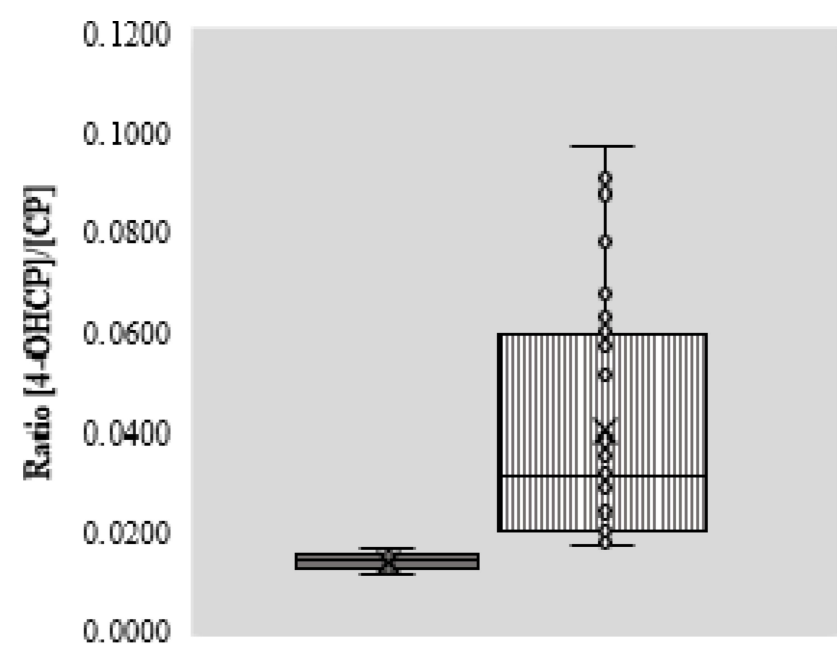

poor metabolizer 血 ultrarapid metabolizer

Figure 2 Box plot of CP bioactivity ratio [4-OHCP]:[CP] in 4-hydroxylation group of poor metabolizer and ultrarapid metabolizer.

also be caused by other anticancer substances, hemorrhagic cystitis is a severe side effect caused especially by the oxazophosphoric drug class, namely $\mathrm{CP}$ and ifosfamide, to be precise by the urotoxic metabolite acrolein. Acrolein is also a spontaneous (nonenzymatic) $\beta$-elimination product beside 4-OHCP so that the 4-OHCP level also correlates with the acrolein level. It can be assumed that the CP 4hydroxylation rate phenotype affects acrolein metabolite levels and the potential for urological side effects, hemorrhagic cystitis. In many cases, side effects of hemorrhagic cystitis generally occur in $10-40 \%$ of patients receiving high or long-term CP chemotherapy. Hemorrhagic cystitis cases were also found based on indicators of hematuria 
formation with a prevalence of $17.5 \% \quad(n=40)$ at "Dharmais" Cancer Hospital. ${ }^{32}$ It was found that a high number of cases of hemorrhagic cystitis in patients at "Dharmais" Cancer Hospital required several efforts to minimize these side effects. Generally, prevention procedure that can minimize the hemorrhagic cystitis are reducing CP dose, hyperhydration, and administration of a uroprotective drug, mesna, a thiol (sulfhydryl) compound which can neutralize acrolein into a nontoxic thioester compound. Mesna should be used only for chemotherapy with ifosfamide high doses or CP greater than $1000 \mathrm{mg} /$ $\mathrm{m}^{2.33}$ Reducing the $\mathrm{CP}$ dose for patients at Dharmais Cancer Hospital is not suggested because the dose has been relatively low $\left( \pm 500 \mathrm{mg} / \mathrm{m}^{2}\right)$ so it is more advisable to give mesna accompanied by hyperhydration on patients while undergoing chemotherapy.

The clear correlation study of the phenotypes on DME metabolism can facilitate personalized medicine. If the DME metabolism shows a strong phenotype-genotype correlation, then only by analyzing the patient's DME genetic polymorphisms, the physicians can determine the dose for personalized medicine. Clinically, phenotypic metabolism studies have advantages over genotypes because they can directly and significantly describe DME capacity/activity through blood drug levels which correlate directly with the effectiveness and toxicity of therapy in patients. This is due to genetic factors are only one of several confounding factors that influence the metabolic pharmacokinetics of drugs. ${ }^{7,23}$ The DME metabolic phenotype study itself has limitations because biomatrix sampling can only be carried out within a certain time, namely when $t_{\max }$ of analyte is achieved after drug administration, bioanalysis costs are relatively expensive, and the need for special handling (sampling, transportation, and storage) with the right techniques and conditions, and analysis as soon as possible to maintain the stability of the analyte in the biomatrix. In contrast, practically speaking, the genotyping study of DME metabolism has the advantage because the analysis is faster, easier, simpler, and relatively low-cost than phenotyping study. Genotype studies are also practical because sampling and analysis can be carried out at any time without the need for prior drug administration to the patient. We suggested that this phenotyping study of $\mathrm{CP}$ 4-hydroxylation should be continued by doing genotyping study (CYP2B6 gene polymorphism analysis) and with a larger quantity of subjects to strengthen the data analysis and obtain a correlation between the phenotype of drug metabolic capacity (activity) and the genetic polymorphism of DME.

\section{Conclusion}

The results showed the cyclophosphamide 4-hydroxylation rate of $80 \%(n=32)$ subjects as UM and $20 \%(n=8)$ as PM. It can be concluded that in Malay cancer patients, cyclophosphamide would be bioactivated through 4-hydroxylation in hepar rapidly as indicated by the high value of the bioactivity ratio or the increased $\mathrm{CP}$ clearance and 4OHCP level.

\section{Abbreviations}

4-OHCP, 4-hydroxycyclophosphamide; AC, adriamycin +cyclophosphamide; CP, cyclophosphamide; CV, coefficient of variance; DBS, dried blood spot; diff, difference/bias; EM, extensive metabolizer; EMEA, European Medicines Agency; ESI, electrospray ionization; FAC, fluorouracil +adriamycin+cyclophosphamide; LLOQ, lower limit of quantification; $\mathrm{m} / \mathrm{z}$, ass per charge ratio; MRM, multiple reaction monitoring; MS/MS, tandem mass spectrometry; $\mathrm{PM}$, poor metabolizer; QC, quality control; $\mathrm{QCH}$, quality control high; QCL, quality control low; QCM, quality control medium; RCHOP, rituximab+cyclophosphamide+adriamycin+vincristine+prednisone; $\mathrm{SN}$, subject number; TAC, docetaxel+adriamycin+cyclophosphamide; TC, docetaxel +cyclophosphamide; ULOQ, upper limit of quantification; UM, ultrarapid metabolizer; UPLC, ultra high performance liquid chromatography.

\section{Ethics}

This study was reviewed and approved by the Research Ethics Committees of "Dharmais" Cancer Hospital, Jakarta 11,420, Indonesia (No. 150/KEPK/VII/2019). This study was conducted in accordance with the Declaration of Helsinki.

\section{Acknowledgments}

This study was supported by Directorate of Research and Community Services (DRPM) Universitas Indonesia with grant number: NKB-2095/UN2.RST/HKP.05.00/2020 and Dharmais Cancer Hospital, Jakarta, Indonesia.

\section{Disclosure}

The authors report no conflicts of interest in this work. 


\section{References}

1. International Agency for Research on Cancer (IARC). IARC Monographs - 100A: Cyclophosphamide. Paris: IARC-WHO; 2012.

2. de Jonge ME, van Dam SM, Hillebrand MJX, et al. Simultaneous quantification of cyclophosphamide, 4-hydroxycyclophosphamide, N, N',N"-triethylenethio-phosphoramide (thiotepa) and N, N', N"triethylenephosphoramide (tepa) in human plasma by high-performance liquid chromatography coupled with electrospray ionization tandem mass spectrometry. J Mass Spectrom. 2004;39:262-271. doi: $10.1002 /$ jms. 570

3. Ekhart C, Doodeman VD, Rodenhuis S, Smits PH, Beijnen JH, Huitema AD. Influence of polymorphisms of drug metabolizing enzymes (CYP2B6, CYP2C9, CYP2C19, CYP3A4, CYP3A5, GSTA1, GSTP1, ALDH1A1 and ALDH3A1) on the pharmacokinetics of cyclophosphamide and 4-hydroxycyclophosphamide. Pharmacogenet Genomics. 2008;18(6):515-523. doi:10.1097/FPC.0b013e3282fc9766

4. Emadi A, Jones RJ, Brodsky RA. Cyclophosphamide and cancer: golden anniversary. Nat Rev Clin Oncol. 2009;6:638-647.

5. Harahap Y, Samuel C, Andalusia R, Syafhan NF. Analysis of 4hydroxycyclophosphamide in cancer patients plasma for therapeutic drug monitoring of cyclophosphamide. Int J Pharm Pharm Sci. 2016;8(9):194-200. doi:10.22159/ijpps.2016v8i9.12918

6. Nakajima M, Komagata S, Fujiki Y, et al. Genetic polymorphisms of CYP2B6 affect the pharmacokinetics/pharmacodynamics of cyclophosphamide in Japanese cancer patients. Pharmacogenet Genomics. 2007;17(6):431-445. doi:10.1097/FPC.0b013e328045c4fb

7. Coleman MD. Human Drug Metabolism. 2nd ed. USA: Wiley; 2010.

8. Mehlotra RK, Ziats MN, Bockarie MJ, Zimmerman PA. Prevalence of CYP2B6 alleles in malaria-endemic populations of West Africa and Papua New Guinea. Eur J Clin Pharmacol. 2006;62:267-275.

9. Zanger UM, Klein K. Pharmacogenetics of cytochrome P450 2B6 (CYP2B6): advances on polymorphisms, mechanisms, and clinical relevance. Front Genet. 2013;4:24. doi:10.3389/fgene.2013.00024

10. de Jonge ME, Huitema ADR, Rodenhuis S, Beijnen JH. Clinical pharmacokinetics of cyclophosphamide. Clin Pharmacokinet. 2005;44(11):1135-1164. doi:10.2165/00003088-200544110-00003

11. Helsby NA, Yong M, van Kan M, de Zoysa JR, Burns KE. The importance of both CYP2C19 and CYP2B6 germline variations in cyclophosphamide pharmacokinetics and clinical outcomes. Br J Clin Pharmacol. 2019;1-10.

12. Haroun F, Al-Shaar L, Habib RH, et al. Effects of CYP2B6 genetic polymorphisms in patients receiving cyclophosphamide combination chemotherapy for breast cancer. Cancer Chemother Pharmacol. 2015;75:207-214. doi:10.1007/s00280-014-2632-4

13. Lang T, Klein K, Fischer J, et al. Extensive genetic polymorphism in the human CYP2B6 gene with impact on expression and function in human liver. Pharmacogenetics. 2001;11:399-415. doi:10.1097/ 00008571-200107000-00004

14. Hiratsuka M, Takekuma Y, Endo N, et al. Allele and genotype frequencies of CYP2B6 and CYP3A5 in the Japanese population. Eur J Clin Pharmacol. 2002;58:417-421. doi:10.1007/s00228-0020499-5

15. Lamba V, Lamba J, Yasuda K, et al. Hepatic CYP2B6 expression: gender and ethnic differences and relationship to CYP2B6 genotype and CAR (constitutive androstane receptor) expression. J Pharmacol Exp Ther. 2003;307:906-922. doi:10.1124/jpet.103.054866

16. Hananta L, Astuti I, Sadewa AH, et al. The Prevalence of CYP2B6 Gene Polymorphisms in Malaria-endemic Population of Timor in East Nusa Tenggara Indonesia. Osong Public Health Res Perspect. 2018;9(4):192-196. doi:10.24171/j.phrp.2018.9.4.08
17. Melanson SEF, Stevenson K, Kim H, et al. Allelic variations in CYP2B6 and CYP2C19 and survival of patients receiving cyclophosphamide prior to myeloablative hematopoietic stem cell transplantation. Am J Hematol. 2010;85(12):967-971. doi:10.1002/ajh.21889

18. Elmaagacli AH, Koldehoff M, Steckel NK, Trenschel R, Ottinger H, Beelen DW. Cytochrome P450 2C19 loss of function polymorphism is associated with an increased treatment-related mortality in patients undergoing allogeneic transplantation. Bone Marrow Transplant. 2007;40:659-664. doi:10.1038/sj.bmt.1705786

19. Zanger UM, Klein K, Saussele T, Blievernicht J, Hofmann M, Schwab M. Polymorphic CYP2B6: molecular mechanisms and emerging clinical significance. Pharmacogenomics. 2007;8:743-759. doi:10.2217/14622416.8.7.743

20. Xie H, Griskevicius L, Stahle L, et al. Pharmacogenetics of cyclophosphamide in patients with hematological malignancies. Eur J Pharm Sci. 2006;27:54-61. doi:10.1016/j.ejps.2005.08.008

21. Ariyoshi N, Miyazaki M, Toide K, Sawamura Y-I, Kamataki T. A single nucleotide polymorphism of CYP2B6 found in Japanese enhances catalytic activity by autoactivation. Biochem Biophys Res Commun. 2001;281:1256-1260. doi:10.1006/bbrc.2001.4524

22. Xie HJ, Yasar U, Lundgren S, et al. Role of polymorphic human CYP2B6 in cyclophosphamide bioactivation. Pharmacogenomics $J$. 2003;3:53-61. doi:10.1038/sj.tpj.6500157

23. de Andres F, Teran S, Hernandez F, Teran E, LLerena A. To genotype or phenotype for personalized medicine? CYP450 drug metabolizing enzyme genotype-phenotype concordance and discordance in the ecuadorian population. OMICS. 2016;20:699-710. doi:10.1089/ omi.2016.0148

24. Su G, Min H, Xin L, Xiao C, Eli C, Shu-Feng Z. Intra- and interethnic differences in the allele frequencies of cytochrome P450 2B6 gene in Chinese. Pharm Res. 2006;23(9):1983-1990. doi:10.1007/ s11095-006-9083-5

25. Sofro ASM. Population Genetic Studies in Indonesia [Dissertation]. Canberra: Australian National University; 1982.

26. Koentjaraningrat. MetodePenelitian Masyarakat. Jakarta: Gramedia Pustaka Utama; 1997.

27. EMEA. Guideline on Bioanalytical Method Validation. EMEA; 2011.

28. FDA. Bioanalytical Method Validation Guidance. FDA; 2018.

29. Joy M, La M, Wang J, Bridges A, Hu Y, Hogan S. Cyclophosphamide and 4-hydroxycyclophosphamide pharmacokinetics in patients with glomerulonephritis secondary to lupus and small vessel vasculitis. Br J Clin Pharmacol. 2012;74(3):445-455. doi:10.1111/j.1365-2125.2012.04223.x

30. Hall OM, Peer CJ, Fitzhugh CD, Figg WD. A sensitive and rapid ultrahigh - performance liquid chromatography with tandem mass spectrometric assay for the simultaneous quantitation of cyclophosphamide and the 4-hydroxy-cyclophosphamide metabolite in human plasma. $J$ Chromatogr B. 2018;1086:56-62. doi:10.1016/j.jchromb. 2018.04.016

31. BC Cancer Agency. Cancer Drug Manual: Cyclophosphamide. Canada: BC Cancer Agency; 2013.

32. Harahap Y, Yanuar A, Cyril M, Melhan M, Purwanto DJ. Quantification of 3-hydroxypropyl mercapturic acid in the urine of patients with breast cancer to monitor cyclophosphamide toxicity. Ther Drug Monit. 2020;42(4):548-553. doi:10.1097/FTD.0000000 000000737

33. London Cancer. Guidelines for the Administration of Mesna with Ifosfamide and Cyclophosphamide. London: London Cancer; 2014. 


\section{Publish your work in this journal}

Drug Design, Development and Therapy is an international, peerreviewed open-access journal that spans the spectrum of drug design and development through to clinical applications. Clinical outcomes, patient safety, and programs for the development and effective, safe, and sustained use of medicines are a feature of the journal, which has also been accepted for indexing on PubMed Central. The manuscript management system is completely online and includes a very quick and fair peer-review system, which is all easy to use. Visit http://www. dovepress.com/testimonials.php to read real quotes from published authors. 